\title{
Stranger Child Abduction and Guardianship: Accompaniment and Surveillance in attempted and completed cases.
}

\section{Craig J.R. Collie ${ }^{\mathrm{a}}$ and Karen Shalev Greene ${ }^{\mathrm{a}}$}

a Institute of Criminal Justice Studies, University of Portsmouth, Portsmouth, PO1 2UP Emails: craig.collie@ port.ac.uk; karen.shalev-greene@port.ac.uk

\begin{abstract}
The Routine Activity Theory construct of capable guardianship is used to examine the features of 78 cases of stranger child abduction, using an outcome based approach to establishing the effectiveness of various potential sources of guardianship in preventing abduction attempts from becoming completed, and to test widely held and taught beliefs on this subject. Results show that only direct oversight provided by an adult who sees themselves as personally responsible for a child to be a very effective means of abduction prevention, both dissuading and disrupting offences. Guardianship provided by other actors, such as peers and third party passers-by, were not effective. Accompaniment by other children could dissuade offending, but failed to disrupt offences in progress. Sources of natural surveillance were ineffective. The finding regarding the ineffectiveness of peers was particularly surprising. The theoretical and practical implications of these findings are discussed.
\end{abstract}

Key words: Stranger Child Abduction; Surveillance; Routine Activity Theory; Capable Guardianship; Crime Prevention. 


\section{INTRODUCTION}

Stranger child abduction is a type of behaviour that has become of increasing concern to society, and yet remains relatively poorly understood (Best, 1987; Miller, Kurlycheck, Hansen \& Wilson, 2008). This paper conducts an inquiry into the effectiveness of various sources of "guardianship" in resisting or diminishing stranger child abduction, examining not only how well various types of guardianship dissuade offending in the first place, but also asking how much protection is offered once an offence is underway.

Stranger child abduction occurs where a person makes any effort to take unlawful control of a child whom they have had no prior contact with or knowledge of (Newiss \& Traynor, 2013). A child includes anyone under the age of 18 (HM Government, 2015; European Commission, 2013). Abduction is committed regardless of the child's acquiescence since they cannot legally consent to being so controlled (Finkelhor, Hammer \& Sedlak, 2002). The term "guardianship" is used to refer to any actor or object potentially capable of disrupting or preventing a crime event, or otherwise dissuading offenders (Hollis, Felson \& Welsh, 2013; Felson, 1995). The main forms of guardianship examined in this study are "accompaniment", where another actor is directly alongside the victim when they are targeted, and "surveillance", which refers to any actor or object that overlooks the site of the offence. The term "monitoring" is used to describe the situation where a guardian is watching and therefore providing guardianship over a space, victim, or offender (Reynald, 2010). "Dissuasion" occurs when an offence is prevented from occurring in the first place, and "disruption" occurs when an offence is being enacted, but is not completed due to the intervention of a guardian (Reynald, 2010).

In the UK, stranger child abduction is a relatively low incidence offence, with 247 cases being reported to police in the year 2013 (Newiss \& Traynor, 2013). However, 
evidence suggests that a large proportion of cases never come to the attention of police, with the most optimistic estimates indicating that only around one third of cases are ever reported (Gallagher, Bradford \& Pease, 2008). Furthermore, recent findings have shown that reports of child abduction overall have increased dramatically in the past three years with increases of up to $50 \%$ (Newiss \& Collie, 2015; Newiss, 2016).

The key impetus behind this study is to assess the accuracy of messages that are being communicated to children and their custodians as part of educational programs intended to keep children safe from being abducted by strangers (see Newiss, 2014). Such lessons commonly contain messages encouraging children to keep themselves in situations where they are being monitored to some extent. A key problem with this body of work is that it implies that there exists a solid foundation of knowledge or research on which to base these lessons (see, e.g., Tedisco \& Paludi, 1996). However, should one inquire further, they will find no such research base; to date, no structured study has analysed stranger child abduction in such a way as to draw any conclusions regarding the efficacy of any practical advice that can be offered to children or caregivers. It can, therefore, be argued that, at present, certain child safety messages are rooted in common sense rather than research.

The most overt advice refers to accompaniment. To reduce the risk of abduction, children are usually encouraged to travel with adults (e.g., Gross, 2013; National Centre for Missing and Exploited Children (NCMEC), 2015b; Kids Health, 2015), or with other children (e.g., NCMEC 2015; Missing Kids UK, 2015). As recently as $20^{\text {th }}$ July 2015, Exeter police issued advice that children "Do not go off on your own. Always play with other children" (Exeter Press and Echo, 2015).In addition, types of guardianship besides direct accompaniment are also cited as being potentially useful. Members of the public, or "safe adults", are mentioned as a source of protection that children can turn to or seek out when 
they are being victimized (Newiss, 2014). Greater Manchester police (2015) advises children than such adults to seek out would include teachers and police officers

Due to the dearth of research on stranger child abduction specifically, it becomes necessary to examine research from related offending domains in order to ascertain how guardianship operates in dissuading offending against children. Findings from existing studies relating to childhood victimization have reported varying effects of guardianship features, resulting in mixed messages regarding which types of guardianship ought to be considered capable.

Gallagher, Bradford and Pease (2008) found that 2 in every 3 children who had been a victim of stranger child abduction (attempted or completed) were accompanied at the time of the offence, usually by other children but also sometimes ( $10 \%$ of cases) by adults as well. In spite of children being subject to a higher level of guardianship than ever due to a combination of the ubiquity of surveillance technology and an ever-growing parental fear of abduction resulting in near constant monitoring and accompaniment (Dixie, 1999; Foster et al, 2015; Sweeney \& Von-Hagen, 2016), children do not seem to be at any less risk of abduction than in the past (Mackett, 2011), and are perhaps even more at risk (Newiss, 2016).

It has also been pointed out that a notable proportion of child sexual abuse, which is in some ways mechanically similar to child abduction, (see, e.g., Boudreaux, Lord \& Etter, 2000) occurs in settings where there are ostensibly high levels of supervision, with even well trained staff directly responsible for children's welfare failing to prevent the circumstances in which abuse can occur (Smallbone, Marshall \& Wortley, 2013, p202). Abuse is also often perpetrated by offenders who themselves would normally be considered as sources of effective guardianship, i.e., coaches, pastors, and so on (Leclerc, Proulx \& Beauregard, 
2009). Findings such as these seem to indicate that accompaniment and surveillance are of limited use in certain circumstances.

Conversely, several studies examining child sexual abuse have found that guardianship, particularly in the form of accompaniment, dissuades offending (Elliott, Browne \& Kilcoyne 1995; Leclerc, Wortley \& Smallbone, 2011). Interviews with perpetrators of child sexual abuse found that it was desirable to offenders for their victim to be alone (Elliott et al, 1995). In particular, offenders specified victims alone in bathrooms and alone while walking to school as particularly desirable, but if necessary they would utilize strategies intended to isolate a child, even temporarily, from any peers or guardians (Elliot et al, 1995). In fact, the offenders themselves recommended that children be accompanied or perform activities in groups if possible. In particular it was recommended that children never walk alone to school as this was cited by offenders as an ideal circumstance in which to target a victim. These findings imply that guardianship can be very effective in preventing abduction.

As can be seen, there is disparity among findings as to which types of guardianship have a real, tangible association with preventing stranger child abduction, and which have simply been assumed to do so. This is further complicated by the lack of research examining stranger child abduction specifically. This gap in research necessitates urgent assessment of the types of guardianship that could help to protect children.

To facilitate this assessment, a Routine Activity Theory (RAT) perspective will be used. RAT is a theory of offending which posits that where there is a convergence of motivated offender, suitable target, and a lack of capable guardianship, an offence will occur (Clarke \& Felson, 1993). RAT has been found to be of particular relevance to stranger child abduction by Boudreaux, Lord and Dutra (1999), who posited that a child aged 10 is more 
vulnerable to stranger abduction as a result of being granted greater autonomy, thus being less supervised whilst also retaining childhood naiveté that makes them less able to resist an offender's advances or recognize a prejudicial situation (Boudreaux, Lord, \& Dutra, 1999; Heide, Beauregard \& Myers, 2009).

RAT is additionally particularly well suited to the current research question exploring what can protect a child from offending, as it relies on the concept of "capable guardianship". This construct will be used to explore and assess the effectiveness of various sources of potential guardianship in preventing stranger child abduction incidents from being completed that are currently thought to protect children from such harm. While part of the larger RAT model, capable guardianship has increasingly been used to examine and assess factors that are purported to prevent crime (E.g., Reynald \& Elffers, 2016;Reynald, 2011; Smith \& Jorna, 2011; Boakye, 2009).

As Groff (2007) points out, the motivation of an offender is often assumed in discussions involving RAT. For the purposes of discussion, this article assumes that the stranger child abductors discussed in this study were motivated offenders, and that they saw their victims as suitable targets. Given this paper's focus on guardianship and child protection, this approach is felt to be justified.

\section{CAPABLE GUARDIANSHIP}

To preclude an offence from taking place, the mere presence of other actors or sources of surveillance watching over the target is insufficient (Clarke \& Felson, 1993). These sources of potential guardianship must be in some way able to protect the victim, if not by directly intervening then at least by being perceived to increase the risk faced by a would- 
be perpetrator (Kennedy \& Ford, 1990). The qualifier "capable" is extremely important, recognizing that not all forms of guardianship actually prevent offences from occurring.

\section{Sources of Guardianship}

Hollis, Felson \& Welsh (2013) embarked on an in-depth consideration of the construct of the capable guardian. Their review defined capable guardianship as "the presence of a human element which acts - whether intentionally or not - to deter the wouldbe offender from committing “ (Hollis, Felson \& Welsh, p76). This would seem to exclude any non-human source of guardianship. However, Felson defines guardianship as "being exercised by those who serve by simple presence to prevent crime and by absence to make crime more likely" (Felson, 1995, p53, cited by Hollis, Felson \& Welsh, 2013, p66). Capable guardianship could therefore include any factor that engenders a feeling of an illicit activity being watched, and the accompanying perception that this will increase the risk of offending. In this view, any kind of surveillance could potentially disrupt or discourage an offender, although this depends entirely on the offender's perception. Indeed, Hollis-Peel, Reynald, van Bavel, Elffers and Welsh (2011, p55) refer to "human guardianship", implying that other sources of guardianship exist.

This leads to the question of which actors or objects can actually provide capable guardianship. There are varying opinions on this matter. Some sources seem to indicate that capable guardians ought to be a directly present individual (Felson, 1986). Others suggest that capable guardianship can be implied by the environment, i.e., that an object or geographic layout increasing the risk of subsequent intervention can be characterised as a form of guardianship (Jefferey, 1971; Newman, 1972).

This latter, broader perspective has become strongly associated with the practice of designing environments to imply that the area is well defended. This is encapsulated in the 
concept of "natural surveillance" (Clarke, 1995: Felson, 1995). Theoretically, this rests on the notion that the mere feeling of being watched can prevent offending. For instance, a building's windows or entrances come with the possibility that occupants could see a public area, and thus provide natural surveillance (Desyllas, Connoly \& Hebber, 2002). Such features of the environment can also be useful as they increase the "opportunities for capable guardianship", i.e., by increasing line of sight (Reynald, 2011, p136).

\section{Requirements for Capable Guardianship}

It has been found that in order to actually dissuade or disrupt crime, and be considered “capable”, a guardian must possess a number of requisites (Felson, 1986). The first of these is capacity to intervene, i.e., a physical ability to increase the likelihood of interruption. If an offence or suspicious event occurs, the guardians must be able to take effective preventive action. Secondly, human guardians must be able to recognize an offending situation if they are to effectively intervene (see, e.g., Coker, Cook-Craig, Williams, Fisher, Clear, Garcia \& Hegge, 20110; Bennet, Banyard \& Garnhart, 2014). Reynald (2010) argues that, in addition to these, a capable guardian must also be willing to supervise in the first place.

Reynald (2011) makes the important point that an actor's possession of these prerequisites can often be contingent on external, situational, or environmental factors. For instance, a householder is motivated to monitor their house and surrounding vicinity, but may not be so willing if placed outside of that context.

Similarly, willingness to intervene can be contingent on a variety of factors. It can depend on actor's self-perceived effectiveness, which could relate to their training, physical size or strength, and so on (Reynald, 2010). Feelings of social cohesion that would engender 
a feeling of obligation to take action for the "greater good" have also been linked to increased likelihood that a guardian will take preventive action (Reynald, 2011). This latter point is likely very relevant for stranger child abduction, which tends to occur in public spaces with high levels of transient foot traffic (Miller et al, 2008), which could result in limited feelings of social cohesion or obligation to safeguard other actors present.

If a guardian fails to effectively recognize an offending situation, it is unlikely that they will be able to intervene When identifying offences, guardians have been found to look for certain types of behaviours or characteristics, ranging from clothing and ethnicity (Reynald, 2010) to how aggressive or sneaky an individual is behaving (Reynald, 2011). Citing Madriz (1997), Reynald (2010) makes a point that is potentially of extreme relevance to stranger child abduction. When detecting would-be criminals, the judgements of would-be guardians are subject to widely held stereotypes about what a criminal or a crime might look like. Stranger child abduction is subject to a large number of these widespread but misleading stereotypes, i.e., a dirty man in a trench-coat, luring children with candy (see Shutt, Miller, Schreck \& Brown, 2004), which could potentially preclude a potentially useful guardian from recognizing an offence in progress.

In addition to these requirements, there is debate as to whether a guardian can be considered effective based purely on whether they are perceived to be capable. Hollis, Felson and Welsh (2013) suggest that guardianship need only be capable to the extent that it be provided by a human source that could intervene in some way. The mere perception of this in dissuading crime increases a guardian's capability. Tilley (2009) contends that an offender's perception of a guardian's capability is likely more important than their actual material ability to repel an offence. The simple appearance of capability could be sufficient to deter crime (Cass, 2007; Tillyer \& Eck, 2010). However, this also means that even potentially useful 
guardianship can be dismissed by an offender if they believe it can be circumvented (Farrel, Philips \& Pease, 1995).

Finally, a potential guardian's relative sense of responsibility has been linked to their likely effectiveness (Felson, 1986). The more invested the guardian feels toward protecting a space or person, the more intensely they will monitor their charge, which in turn makes them more likely to prevent, detect and disrupt crime (Reynald, 2010). The level of effort a guardian exerts towards providing monitoring or intervention is tied to their self-perceived responsibility (Reynald, 2011). The key debate on this issue regards whether specific, assigned responsibility over a target makes a guardian more discerning than if they had generalized responsibility (Mayhew, 1981; Clarke, 1992), i.e., as Felson posits, those with general responsibility (passers-by, visitors) have no personal interest or professional duty in protecting a target, and therefore may not always do so.

However, following a meta-review Hollis, Felson and Welsh (2013) noted that actors can provide effective guardianship over targets even if they do not feel actively responsible towards them. Whether a guardian intends to dissuade crime is irrelevant, rather, the key factor is whether the actor can be perceived to be capable of effective intervention by wouldbe offenders (Hollis et al, 2013). It has additionally been hypothesized that adults might be more likely to intervene if the subject in distress is a child (Christy \& Voigt, 1994). However, it has been found that bystanders are no more likely to intervene if a child was in distress than another adult (Ross, 1971), and this is particularly true if other bystanders were present as well, i.e., if responsibility is diffuse (Ross, 1971; Christy \& Voigt, 1994). Nevertheless, although there is little direct research on the issue, it could be hoped that adults would be likely to attempt to intervene to prevent an offence as universally feared and demonized as stranger child abduction were to occur (Tedisco \& Paludi, 1996). 
This debate raises important questions for stranger child abduction. The general public, as well as sources of natural surveillance, potentially provide useful guardianship over children, yet it remains uncertain whether they would be capable of sufficiently monitoring areas or intervening in offences in such a way that would enable them to disrupt or dissuade offending and be considered "capable" guardians.

\section{$\underline{\text { Research Questions }}$}

Given the contradictory findings and perspectives identified above, this article seeks to test the impact of various potential sources of guardianship in stranger child abduction cases, by examining the extent to which their presence had a relationship with the outcome of a series of real world offences that occurred in the UK. By doing so, the limits of various types of guardianship can be ascertained.

In order to account for both human and environmental sources of guardianship, the key sources of guardianship to be examined are accompaniment by adults, accompaniment by other children, the presence of sources of natural surveillance, and the presence of members of the public, i.e., those with generalized responsibility.

Particularly with accompaniment, it is necessary not only to examine how often victims are targeted in the presence of various types of accompaniment, but also to ask, when targeted, whether these types of accompaniment having an impact on case outcome. This will allow us to ascertain whether the accompanying guardian can successfully disrupt offending, in addition to just dissuading it.

\section{METHOD}


The study was carried out by performing secondary data analysis of newspaper articles and legal cases pertaining to cases of stranger child abduction that have occurred in the UK. This was used to create a database of convicted offences involving stranger child abductions occurring between 1988 and 2014, with most cases (85\%) having occurred since 2000.

With reference to the definition of stranger child abduction used above, only cases involving victims under the age of 18 at the time of the offence were included.

Searches were performed utilizing the databases Westlaw, Lexis as well as web-based searches using Google, Ask and Yahoo search. Combinations of the key words 'Stranger', 'Child', 'Abduction', 'Sexual', 'Assault' 'Kidnap', 'Charged', 'Guilty' and 'Convicted' were used to source relevant court documents and to identify media outlets reporting on stranger child abduction incidents. The documents used consisted of legal cases and newspaper articles that had been reported online.

Table 1: Search Key Words

\begin{tabular}{lll}
\hline & $\begin{array}{c}\text { Key Words } \\
\text { Searched }\end{array}$ & \\
\hline Stranger & Guilty & Assault \\
Child & Charged & Rape \\
Abduction & Kidnap & Attack \\
\hline
\end{tabular}

Searches of databases of legal cases were carried out using the same search terms. The databases used were Lexis Nexis and Westlaw. Finally, searches of dedicated newspaper archives were carried out. The primary archive utilized was Lexis.

In all instances, the results of the search gave hits that included references and links to other, similar cases which, although not appearing as results to the initial search, were followed up and found to match inclusion criteria. The home sites of the various media 
outlets identified in this manner were searched as well. The outlets represent a mixture of broadsheet and tabloid outlets. 56 outlets were identified and searched, as follows:

Table 2: Local and National UK Media Outlets Searched

\begin{tabular}{lll}
\hline & Media Outlets Searched & \\
\hline The Independent & The Telegraph & $\begin{array}{l}\text { The Birmingham Evening } \\
\text { Mail }\end{array}$ \\
\hline The Guardian & Hull Daily Mail & The Northern Echo \\
\hline The Journal & $\begin{array}{l}\text { Bradford Telegraph \& } \\
\text { Argus }\end{array}$ & The Mirror \\
\hline BBC News & Gloucester Citizen & The Daily Mail \\
\hline The York Press & Morley Observer & Birmingham Mail \\
\hline Walsall Advertiser & Hastings Observer & Bolton News \\
\hline The Northern Echo & Burnley Express & Newham Recorder \\
\hline Wales News & Welwyn Hatfield Times & Lancashire Telegraph \\
\hline Liverpool Echo & North of England News & Dorset Echo \\
\hline Mancunian Matters & The Sun & North Wales Daily Post \\
\hline Northampton Chronicle \& & Yorkshire Evening Post & Yorkshire Post \\
Echo & Huffington Post UK & ITV News \\
\hline Express and Star & Doncaster Free Press & Belfast Telegraph \\
\hline Rotherham Advertiser & Keighley News & Stroud News \& Journal \\
\hline Evening Standard & Wigan Today & Leigh Journal \\
\hline Sunderland Echo & Western Daily Press & Bristol Post \\
\hline Hull Daily Mail & Bury Times & Manchester Evening News \\
\hline Blackpool Gazette & Kent and Sussex Courier & Kent Online \\
\hline Telegraph \& Argus & The Glasgow Herald & \\
\hline The Herald & & \\
\hline
\end{tabular}

This process led to the procurement of sufficient information to compile detailed narrative accounts of 78 cases of stranger child abduction, which were then coded into numerical values for quantitative, statistical analysis with the aid of IBM's SPSS program.

Data was coded for this study utilizing a total of 17 variables. This included the victim's age, victim's gender, offender's age, and whether the offence was completed or attempted. 
Guardianship variables were divided under the headings of accompaniment and surveillance.

Accompaniment included 4 variables: whether there was accompaniment of any kind; accompaniment by other children under 18; accompaniment by an adult, which refers to a person aged over 18; and accompaniment by a group including both children and adults.

Surveillance was split into two groups, intended to compare guardianship types implied by the environment, and the offence actually being witnessed:

Potential surveillance included 7 variables, and recorded sources of surveillance regardless of whether the abduction was witnessed, and included : obvious third party surveillance by individuals not accompanying the victim but who could potentially directly observe the crime site; overlooking windows, doors and other portals through which a witness could potentially observe the crime site, which were recorded under the umbrella term "natural surveillance"; the presence of CCTV; crime sites situated in publically accessible areas; crime sites in crowded locations; direct daylight; features that raise the possibility of pedestrian traffic, such as paths and pavements; features that raise the possibility of vehicle traffic, such as roads.

Actual surveillance referred to cases where there was evidence that the offence had actually been observed or witnessed, and included two variables: The offence was witnessed by a third party who had not been directly accompanying the victim; and the offence was recorded on CCTV.

The power of guardianship is tested by measuring and then comparing the sources of potential guardianship present in completed abductions, and those present in attempted abductions. This enables the guardianship profiles of successful and unsuccessful abductions 
to be measured against one another and for conclusions as to the preventive power of each guardianship feature to be drawn. Additional analysis is carried out by examining abduction completion rates within each guardianship feature in order to account for possible biased produced by offender victim selection strategy, and to measure how often abductions are interrupted in the face of each guardianship source once the offence is underway. This approach will allow examination of the dissuasive power of each source of guardianship in preventing offences occurring in the first place, and to examine their disruptive power against offences in progress.

\section{Limitations}

The methodology has several limitations of which the reader should be aware. It is acknowledged that newspaper articles are not a direct source of information; however, in this case, they represent the best data available at the time of writing for the majority of stranger child abduction incidents. Access to offenders themselves for interview was sought, but arrangements could not be made within the project's timeframe. Police systems were accessed, but did not adequately distinguish stranger cases from other types of child abduction or even from child sexual exploitation so could not be used. Where possible, legal case transcripts were used as the preferred evidence type, however, in the UK, legal cases are only reported and made available should the case form a legal precedent or otherwise comment usefully on how to interpret the law. Unfortunately, only a handful of cases featuring stranger child abduction formed such precedent in order to become part of a law report.

As a result, newspaper and media sources became the best available evidence, as these report on ongoing legal cases, quote police sources, and can be interpreted in order to assess whether the case was a stranger child abduction incident or not. In all cases featured in 
this sample, at least two separate reports from different media outlets or legal sources were required to impose a measure of corroboration.

The sample is quite small. This is partially due to stranger child abduction being a low incidence offence. As outlined, only 247 cases are reported annually in the UK (Newiss \& Traynor, 2013), with only around one third of cases are reported to authorities at all (Gallagher et al, 2008). The absence of a report means there is no documentation available for most occurrences of stranger child abduction. Additionally, most reports of stranger child abduction contain very limited information (Finkelhor \& Ormrod, 2000), and even official police records have issues with the recording of information (Asdigian, Finkelhor \& Sedlak, 1995; Newiss \& Fairbrother, 2004; Fitzgerald \& People, 2006), making detailed analysis difficult.

Measures taken to control quality of sources and ensure as much validity and reliability also limited the size of the sample. The requirement to only include cases with a confirmed judicial conviction, and where a named offender was present, limited the number of cases available for analysis. This was done in order to ensure a level of corroboration, and to mitigate the effects of biased reporting from media and legal outlets by having multiple sources for each case. It is felt that this sample size, given these limitations, is acceptable, and is largely commensurate with the samples utilized in other, similarly detailed studies (e.g., Beauregard, Stone, Proulx\& Michaud, 2008).

As a result of being taken from secondary media and legal sources, it is likely that the sample is skewed towards more serious or newsworthy cases. This limits the generalizability of the sample, especially considering that a significant proportion of abductions go unreported altogether. Additionally, it is possible that media outlets may sensationalize cases to some extent, a factor that is unfortunately impossible to control. It is also likely that these 
sources will have engaged in selective reporting, not communicating every detail of a case. Nevertheless, these shortcomings are unavoidable given that these represent the most detailed sources on these offences currently available that record sufficient information for any analysis to occur.

\section{RESULTS}

\section{SAMPLE FEATURES}

The sample consists of 78 offences. $32.5 \%(n=25)$ were attempted abductions and $67.5 \%(n=53)$ of offences were completed abductions. Some cases involved more than one victim, with 5 cases having 2 victims, and 1 case having 3 victims.

83 victims in the sample were aged between 2 and 17 years, with an average age of 10.582 years $(\mathrm{SD}=3.02) .46 .9 \%$ of victims were male, and $53.1 \%$ were female. $42.5 \%$ were aged between $0-10,48.8 \%$ were between $48.8 \%$, and $8.8 \%$ were aged $15-17$.

Offenders $(n=53)$ were exclusively male, and were aged between 19 and 59 years with an average age of 35.05 years $(\mathrm{SD}=10.582) .49 .1 \%$ were aged $18-30$ years, $38.2 \%$ were aged $31-49$ years, and $12.7 \%$ were aged 50 years or over.

\section{VICTIM ACCOMPANIMENT}

In terms of frequency of accompaniment in all cases of stranger child abduction, $67.9 \%(n=53)$ of victims were not accompanied at the time of the offence. $20.5 \%(n=16)$ were accompanied by children, $6.4 \%(\mathrm{n}=5)$ by adults, and $5.1 \%(\mathrm{n}=4)$ by a combination of children and adults. Data was not available for 5 victims. 
A comparison of the proportions of accompaniment present in completed cases measured against attempted cases enables analysis of the dissuasive power of various accompaniment sources.

Table 3- Accompaniment in Completed and Attempted Cases of Abduction

\begin{tabular}{lcc}
\hline $\begin{array}{c}\text { Type of } \\
\text { Accompaniment }\end{array}$ & $\begin{array}{c}\text { Proportion of Completed } \\
\text { Cases }\end{array}$ & $\begin{array}{c}\text { Proportion of Attempted } \\
\text { Cases }\end{array}$ \\
\hline Unaccompanied & $74 \%(\mathrm{n}=37)$ & $61.54 \%(\mathrm{n}=16)$ \\
Other Children & $22 \%(\mathrm{n}=11)$ & $15.38 \%(\mathrm{n}=4)$ \\
Parent Or Guardian & $2 \%(\mathrm{n}=1)$ & $11.54 \%(\mathrm{n}=3)$ \\
Adults and Children & $2 \%(\mathrm{n}=1)$ & $11.54 \%(\mathrm{n}=3)$ \\
Total & $100 \%(\mathrm{n}=50)$ & $100 \%(\mathrm{n}=26)$ \\
\hline
\end{tabular}

Data on accompaniment was available for 50 completed cases. Table 3 shows that, of these, $74 \%$ of cases featured unaccompanied victims $(n=37)$, with a combined $26 \%(n=16)$ featuring accompanied victims. Within the accompanied cases, a large majority of $84.6 \%$ featured other children only.

In attempted cases, a marginally smaller number of cases featured unaccompanied victims at $61.53 \%(\mathrm{n}=16) .15 .38 \%(\mathrm{n}=4)$ featured accompaniment by only other children, which is a slightly lower rate than that observed in completed cases, however, a relatively large number of attempted cases featured accompaniment by adults $(11.54 \%)$ or by adults and other children (11.54\%). Within accompanied cases, proportionately half as many cases $(40 \%)$ featured accompaniment by peers alone, while $60 \%$ featured an adult guardian.

This comparison reveals that a largely similar profile of accompaniment is shared between completed and attempted cases. There is a large preference for lone victims in each group. Somewhat similar rates of offenders will target victims accompanied by peers alone, with this occurring marginally more often in completed cases. The most notable variation is 
that offenders in completed cases are very unlikely to target victims accompanied by an adult, whereas offenders in attempted cases will do so in a fifth of cases.

This analysis reveals little that is not already known about stranger child abduction and accompaniment, speaking mostly to their relative proportions and to initial target selection. These results simply confirm that children are likely to be unaccompanied when they are targeted for abduction, and that peers are less effective guardians than adults.

In order to provide a more thorough analysis, it is necessary to examine the variations of abduction completion rates within each type of accompaniment. This is necessary as purely comparative rates may be skewed by the offender's initial target selection strategy. The success of each accompaniment type once the abduction is underway is necessary to analyse their ability to disrupt offence that is being enacted.

Table 4- Completion Rates within Each Accompaniment Type

\begin{tabular}{|c|c|c|c|c|c|}
\hline & $\begin{array}{c}\text { Unaccompani } \\
\text { ed }\end{array}$ & $\begin{array}{c}\text { Accompanie } \\
d\end{array}$ & $\begin{array}{c}\text { Other } \\
\text { Children }\end{array}$ & $\begin{array}{l}\text { Parent or } \\
\text { Guardian }\end{array}$ & Both \\
\hline $\begin{array}{l}\text { Complet } \\
\text { ed }\end{array}$ & $69.81 \%(\mathrm{n}=37)$ & $\begin{array}{c}56.57 \% \\
(\mathrm{n}=14)\end{array}$ & $\begin{array}{c}68.75 \% \\
(\mathrm{n}=11)\end{array}$ & $20 \%(\mathrm{n}=1)$ & $25 \%(\mathrm{n}=1)$ \\
\hline $\begin{array}{l}\text { Attempte } \\
\text { d }\end{array}$ & $30.19 \%(n=16)$ & $\begin{array}{c}43.43 \% \\
(n=11)\end{array}$ & $31.25 \%(\mathrm{n}=5)$ & $80 \%(n=4)$ & $75 \%(n=3)$ \\
\hline Total & $100 \%(\mathrm{~N}=53)$ & $\begin{array}{c}100 \% \\
(\mathrm{~N}=25)\end{array}$ & $100 \%(\mathrm{~N}=16)$ & $100 \%(\mathrm{~N}=5)$ & $\begin{array}{l}100 \% \\
(\mathrm{~N}=4)\end{array}$ \\
\hline
\end{tabular}

Table 4 shows the results for case outcome within each type of abduction. In cases where the victim was not accompanied, the abduction element of the offence was completed in $69.81 \%(n=37)$ of the time. Moreover, when other children were present, the abduction was completed in $68.75 \%$ of cases $(n=11)$. However, when a parent or guardian was present, the abduction was completed in only a single case. When accompanied by both children and adults, the offence was completed $25 \%$ of the time $(n=1)$. The form of accompaniment was 
found to significantly interact with case outcome via linear-by-linear association $(p=0.017)$, however, the numbers of offences were too small to give statistically significant readings for individual forms of accompaniment.

\section{POTENTIAL SURVEILLANCE}

\section{Table 5- Surveillance in Stranger Child Abduction}

\begin{tabular}{|c|c|c|c|c|c|}
\hline & & $\begin{array}{l}\text { Presence in } \\
\text { All Cases }\end{array}$ & $\begin{array}{c}\text { Presence in } \\
\text { Attempted } \\
\text { Cases }\end{array}$ & $\begin{array}{c}\text { Presence in } \\
\text { Completed } \\
\text { Cases }\end{array}$ & $\begin{array}{l}\text { Completion Rates } \\
\text { Where Present }\end{array}$ \\
\hline & $\begin{array}{c}\text { Pedestrian } \\
\text { Traffic }\end{array}$ & $33.80 \%$ & $55.56 \%$ & $22.00 \%$ & $37.5 \% *$ \\
\hline Potential & $\begin{array}{c}\text { Natural } \\
\text { Surveillanc } \\
\mathrm{e}\end{array}$ & $72.70 \%$ & $81.50 \%$ & $68.00 \%$ & $60 \%$ \\
\hline \multirow[t]{4}{*}{$\begin{array}{l}\text { Surveillan } \\
\text { ce }\end{array}$} & $\begin{array}{l}\text { Public } \\
\text { Area }\end{array}$ & $97.40 \%$ & $96.30 \%$ & $97.40 \%$ & $65.79 \%$ \\
\hline & $\begin{array}{l}\text { Crowded } \\
\text { Location }\end{array}$ & $24.40 \%$ & $33.30 \%$ & $19.60 \%$ & $52.63 \%$ \\
\hline & $\begin{array}{c}\text { CCTV } \\
\text { Cameras }\end{array}$ & $27 \%$ & $25.90 \%$ & $28 \%$ & $66.67 \%$ \\
\hline & Passers-by & $93.50 \%$ & $96.29 \%$ & $92 \%$ & $63.89 \%$ \\
\hline $\begin{array}{c}\text { Actual } \\
\text { Surveillan } \\
\text { ce }\end{array}$ & Witnessed & $38.50 \%$ & $77.78 \%$ & $17.60 \%$ & $30 \% * *$ \\
\hline
\end{tabular}

Table 5 shows that, of the potential sources of surveillance, only pedestrian traffic at the abduction initiation had a significant relationship with case outcome $(p=0.003)$. This was present in $33.80 \%$ of cases overall, appearing in far more attempted cases $(55.56 \%)$ than completed ones $(22.00 \%)$. This appears to indicate that pedestrian traffic can be an effective means of dissuading offenders in stranger child abduction. This of particular interest as this was the only type of potential surveillance to appear useful, and, it is the only one that directly involves human actors as the source of supervision. 
The presence of natural surveillance such as overlooking doors and windows was not strongly associated with case outcome. Such ambient surveillance was present in a majority of cases overall (72.70\%), although observed somewhat more often in attempted cases $(81.50 \%)$ than completed ones $(68.00 \%)$.

A number of other features that represent potential sources of surveillance that might be expected to dissuade offenders were found not to have a significant association with case outcomes. These included: daylight; offence site in public area; crowded crime site; CCTV coverage; potential for passers-by (i.e., roads, pavements, thoroughfares near to crime site).

This suggests, then, that natural surveillance and other types of guardianship implied by the environment is not effective at discouraging stranger child abduction incidents, making for a surprising refutation of natural surveillance literature as it pertains to this type offending.

\section{ACTUAL SURVEILLANCE-BEING WITNESSED OR BEING CAUGHT ON CCTV}

The offence being witnessed by a party other than the victim or someone directly accompanying them had a strong association with whether the offence was attempted or completed $\left(X^{2}(1, \mathrm{~N}=78)=26.969, p<0.001\right)$. In attempted cases, the offence was witnessed by another party $77.78 \%$ of the time, compared to completed cases which were only witnessed $17.60 \%$ of the time. Thus, cases that were witnessed had a low completion rate at only $30 \%$. Based on this, the offence being witnessed is one of the most discerning protective factors in determining case outcome. 


\section{DISCUSSION}

Concepts from RAT help us understand stranger child abduction in a number of ways. Firstly, the findings from this study indicate that the matter of offender perception can be particularly important in stranger child abduction, and that offenders are unlikely to perceive a number of potentially dissuasive sources as being capable. Secondly, the findings indicate that, as implied be Felson (1995) and Hollis et al (2013), that human guardians are best able to defend children, and that their effectiveness is related to how responsible they feel for defending the child in question. Thirdly, they show that, once the offence is underway, some forms of guardianship, particularly that provided by other children, are not capable of further disrupting or preventing the offence, even if they do appear to dissuade a large proportion of offences from occurring in the first place.

In terms of the power of accompaniment, our findings (see Table 3 above) showed similar profiles of accompaniment between attempted cases and completed cases. Attempted and completed cases both featured predominantly lone victims, with relatively low levels of accompaniment by adults or by children present in cases that do go ahead. The most important implication of this is, since offenders appear to favour targeting victims who are not accompanied, that accompaniment dissuades offences from being enacted in the first place. Accompaniment of any kind appears to prevent offences from occurring, and these possess dissuasive properties.

However, the findings also indicate that accompaniment by adults is more successful in preventing offences than accompaniment by other children. Offences are enacted against victims accompanied by their peers alone at a far higher rate than against those with an adult present. Furthermore, when comparing attempted and completed cases, when an abduction 
offence was enacted in the presence of an accompanying adult, victims were six times as likely as when accompanied by child peers, to escape and thus be successfully guarded. Conversely, accompaniment by children appeared to lack disruptive qualities, indicating that children are not capable guardians over their peers should an abduction attempt be enacted.

\section{VICTIM ACCOMPANIMENT AND THE ROLE OF OFFENDER PERCEPTION AND}

\section{MOTIVATION}

The findings regarding the effectiveness of different types of victim accompaniment had important implications for RAT. In particular, they indicated that capability of guardianship in stranger child abduction is highly contingent on offender perception (Yar, 2014), and that this can vary depending on how determined an offender is.

As one might expect, the results show that lone children were targeted more often than children who had any form of accompaniment. This has the relatively straightforward implication of suggesting that direct guardianship over a child, regardless of who provides it, has a strong role in dissuading offending in the first place, whereas its absence appears to encourage motivated offenders to take an offending opportunity. Similarly expected was that these lone targets are at high risk of the abduction attempt against them being successful.

The findings regarding the role of adult accompaniment were also fairly straightforward. Abduction cases involving accompaniment by adults were rare, indicating that most offenders would be unlikely to try to abduct a directly supervised child at all. In the rare cases where such abductions were undertaken, accompaniment by an adult was strongly associated with an offence being prevented, suggesting that adults in charge of children will recognize a prejudicial situation and intervene effectively, thus making them capable guardians in most cases. 
However, the results pertaining to children accompanied by their peers, i.e., by other children, were somewhat more complicated. The results indicate that offenders do appear to prefer lone victims, indicating that the presence of peers can dissuade offending from occurring in the first place. However, should an offender decide to undertake an offence in the presence of a child's peers, they will encounter little resistance and be able to complete the offence a large majority of the time. This indicates that children should still travel in groups, but that additional measures ought to be taken to encourage children to more effectively protect one another, i.e., by calling for help, saying no to the offender, or by encourage one another to run away. This finding is also interesting in that children can be effective guardians even though they lack the capacity to intervene; the perception that they might take preventive action, even though they often do not, is sufficient to deter most offenders.

With regard to RAT and the concept of guardianship, there is a potentially interesting contrast when we consider how often children accompanied by their peers are successfully abducted, compared to how often they are targeted at all. When compared proportionately to other forms of accompaniment in terms of how often they helped resist an offence, children who were accompanied by peers were successfully targeted by abductors at a similar rate as lone victims. This suggests that, in fact, children are not capable guardians and they are rarely able to disrupt abduction incident once it is initiated by the offender.

However, when we consider how often victims accompanied by their peers are targeted in the first instance, we can draw a further conclusion. The present findings suggest that children accompanied by peers are targeted less often than previous studies indicate, contrasting most significantly with the rates found by Gallagher et al(2008), who showed that children were targeted whilst accompanied by peers in $66 \%$ of all stranger child abduction cases, whereas the present findings found a rate of approximately 33\%, or half as often. This 
suggests that accompaniment by other children may be providing some level of perceived guardianship, since offenders still appear to favour unaccompanied victims where possible.

In terms of the applying the concept of capable guardianship to stranger child abduction, then, this means that a source of guardianship, despite being a provably ineffective source of protection over a target, can still be a capable guardian if they are perceived as such by offenders. In other words, they can stop an offence from being initiated in the first place, but become far less useful once the decision to offend has been made. This highlights the importance of an offender's perception of guardianship in stranger child abduction, affirming suggestions made by authors such as Tilley (2009), Cass (2007) and Yar (2014).

\section{SURVEILLANCE AND THE ROLE OF DIRECT SUPERVISION}

Overall findings for victim surveillance also had important implications for RAT. They appear to demonstrate a number of key points. Firstly, the results indicate that all of the effective types of guardianship involved human actors, whilst non-sentient forms of guardianship were not determinative or dissuasive. Secondly, the results showed that guardianship provided by direct supervision over a child was more effective than that provided by passers-by or other more general sources.

Hence, the primary finding was that anything short of direct, clear and obvious surveillance by a third party would not be influential in determining the outcome of the case. The main theoretical implication of this finding, in terms of capable guardianship, is that offenders do not perceive anything short of direct guardianship to be effective. Indirect or potential guardianship is not effective in stranger child abduction. As such, natural surveillance principles do not seem to be in effect for this offence, with Felson's (1986) and Hollis, Felson \& Welsh's (2013) perspective that capable guardianship ought to involve the 
presence of a human seemingly in effect. This further supports Hollis-Peel \& Welsh's (2014) notion of differentiating direct and indirect intervention.

In practical terms, this is particularly concerning considering that the vast majority of cases were found to be initiated in locations with at least some base level of natural surveillance, tending to move to secluded areas later as offences progressed.

In stranger child abduction cases, therefore, the perspective that perception of effective guardianship can be effective appears to be mostly untrue. The guardian must be literally capable in order to adequately prevent offending.

Furthermore, the level of passer-by intervention, even when the offence is observed, is quite low. It seems, then, that passers-by would fall into the category of either unmotivated guardians who are unwilling to intervene, or unaware guardians who cannot tell an offending incident from a benign event, or some combination where they will not exert the effort required to discern one from the other, preferring to dismiss the event or leave it to other, more directly responsible caregivers. In either case, the findings suggest that generalized guardianship is ultimately quite ineffective in preventing stranger child abductions, with offenders willing to proceed with an offence in face of such supervision over the target, and not being stopped or challenged when they do so. To be effective, guardians must have a greater level of direct involvement with the target, i.e., be more personally responsible. It would be very useful to find a means by which to encourage third-party intervention, or to increase the extent to which adults feel obligated to recognize and monitor potentially suspicious incidents (see Reynald, 2010; Leclerc \& Reynald, 2015).

Even direct guardianship is not always effective, particularly if that guardianship is provided by another child. Guardianship provided by other children was neither perceived to be effective by offenders, nor was it proven to be effective in practice. In other words, based 
on these findings, in most cases it appears as though children cannot be conceptualized as offering capable guardianship over their peers.

That said, there was a trend towards offenders preferring to target victims who were not directly supervised, even if said supervision was ineffective. Most victims were alone and not being obviously observed, even if they were in locations featuring natural surveillance or with high risk of pedestrian traffic.

It is not entirely clear from the data, but it is likely that a large number of offences were observed by third parties, who are potential guardians, but were not reported to authorities. It can therefore be suggested that a significant proportion of third party guardians, who would be considered to be general guardians using Felson's typologies (1995), do not understand that what they have observed is a serious criminal offence.

This is particularly interesting at it would be hoped that in situations where a child is at risk, general members of the public would feel mandated to intervene in some manner. It could be hypothesized that this effect would be even stronger in the presence of a stranger child abduction incident, which is a widely feared offence type. The current findings, however, support previous studies (e.g., Ross, 1971; Christy \& Voight, 1994) that have found that bystanders are not likely to intervene in such situations. From this, it can be concluded that the assumption that third party bystanders will intervene to protect children in the face of stranger child abduction is not a safe one, and that such actors should not be relied on to defend children, and that the mere fact a child is at risk is not normally sufficient to motivate such bystanders to intervene. This also supports Reynald's (2011) point that more invested guardians are likely to monitor their charge with increased intensity and, therefore, provide more capable guardianship. 
The findings leave us with another pressing issue, namely that of why some offenders are prepared to attempt to abduct a child who is ostensibly well guarded. This raises questions as to whether and why offenders do not perceive the presence as sufficient to constitute capable guardianship in these cases. We can begin to answer this by inquiring into our findings regarding victimization type, specifically by comparing attackers who use coercive means such as assault and threat, and those who use non-coercive means, such as lures and manipulation (Tedisco \& Paludi, 1996; Hanfland et al, 1997).

The findings also indicate that, while there is a general preference towards lone, vulnerable victims of opportunity, there exists a smaller sub-set of highly motivated or fixated offenders who are driven to target and abduct a victim even in the face of strong adult supervision. The question of how to dissuade or resist these offenders is difficult.

\section{CONCLUDING REMARKS}

The findings from this study suggest there are few true "capable guardians" against stranger child abduction that are likely to be actually present at an offence in progress. Any guardianship short of direct adult supervision with immediate responsibility towards a child is highly inconsistent in its effectiveness. Furthermore, the notion that surveillance ought to be from an animate source, i.e., a human, is supported by the current study. Natural surveillance seems to play a very limited role in stranger child abduction. Felson's (1995) hierarchy of guardianship is also supported, as guardians with greater responsibility towards a target proved to be more effective at preventing stranger child abductions against them.

While it was shown that surveillance and monitoring can sometimes be perceived to be effective and thereby reduce offending, this occurs with little consistency, and should an offender proceed with their abduction attempt, they are unlikely to be challenged. These 
findings are or particular concern as they indicate that a number of assumptions that have been made regarding child protection, especially the lesson that accompaniment by peers is an effective form of guardianship, are false and inappropriate. Going forward, it will be useful to acknowledge this difference between the softer prevention by perception, and more direct prevention by intervention when considering sources of guardianship in stranger child abduction.

With this in mind, it should be emphasised that, since stranger child abduction is an extremely heterogeneous type of behaviour, it is extremely difficult to make specific, proactive recommendations to reduce the success rates of stranger child abduction. Advice that could be useful in one instance of stranger child abduction may put the victim at greater risk in another. As such, even recommendations that might seem obvious and intuitive based on these findings, such as increasing the chances that members of the public or other general custodians, such as store clerks, will intervene in possible cases of stranger child abduction, or improving the effectiveness of children in defending their peers, must be made with great caution and consideration. For this reason, this paper makes no practical recommendations beyond simply stating that the presence of motivated adult guardians decreases the risk of stranger child abductions becoming completed, and even then there are some cases where a highly motivated offender will not be adequately deterred.

It should be kept in mind that this research examines offenders who have tried to abduct a victim, so does not reflect the extent to which offenders who wished to carry out such a crime were dissuaded from doing so. This raises the possibility for future research examining the extent to which varying levels of offender motivation or fixation interact with guardianship features.

\section{REFERENCES}


Asdigian, N. L., Finkelhor, D., \& Hotaling, G. (1995).Varieties of nonfamily abduction of children and adolescents. Criminal Justice and Behavior, 22(3), 215-232.

Banyard, V.L. (2011). Who will help prevent sexual violence: Creating an ecological model of bystander intervention. Psychology of violence, 1(3), 216-229.

Beauregard, E., Stone, M.R., Proulx, J., \& Michaud, P. (2008).Sexual Murderers of Children Developmental, Precrime, Crime, and Postcrime Factors. International Journal of Offender Therapy and Comparative Criminology, 52(3), 253-269.

Boakye, K. A. (2009). The concept of capable guardianship: Exploring police views on tourist protection in Ghana. Crime Prevention \& Community Safety, 11(2), 104-123.

Boudreaux, Monique C., Robin L. Dutra, and Wayne D. Lord. "Child abduction: Aged-based analyses of offender, victim, and offense characteristics in 550 cases of alleged child disappearance." Journal of Forensic Science 44.3 (1999): 539-553.

Boudreaux, M. C., Lord, W. D., \& Etter, S. E. (2000). Child abduction: An overview of current and historical perspectives. Child Maltreatment, 5(1), 63-71.

Cass, A.I. (2007). Routine activities and sexual assault: An analysis of individual- and school-level factors. Violence and Victims, 22(3), 350-366.

Christy, C. A., \& Voigt, H. (1994).Bystander responses to public episodes of child abuse. Journal of Applied Social Psychology, 24, 824-847. 
Clarke, R.V. (1992). Situational Crime Prevention: Successful Case Studies.

Albany, NY: Harrow and Heston.

Cohen, L., \& Felson, M. (1979).Social change and crime rate trends: A routine activity approach. American Sociological Review, 44, 588-608.

Coker, A.L., Cook-Craig, P.G., Williams, C.M., Fisher, B.S., Clear, E.R., Garcia, L.S., \& Hegge, L.M. (2011). Evaluation of Green Dot: An active bystander intervention to reduce sexual violence on college campuses. Violence Against Women, 17(6), 777-796.

Clarke, R. V. (1995). Situational crime prevention. Crime and justice, 91-150.

Clarke, R. V., \& Felson M. (Eds.).(1993). Routine activity and rational choice. Advances in criminological theory. New Jersey: Transaction.

Desyllas, J., Connoly, P., \& Hebber, F. (2003).Modelling Natural Surveillance. Environment and Planning B: Planning and Design, 30, pp643-655.

Dixey, R. (1999). Keeping Children Safe The Effect on Parents' Daily Lives and Psychological Wellbeing. Journal of Health Psychology, 4(1), 45-57

Eck, J. E. (1994). Drug markets and drug places: A case-control study of the spatial structure of illicit drug dealing. University of Maryland, Faculty of the Graduate School. 
Eck, J. E. (1995). Examining routine activity theory: A review of two books. Justice Quarterly, 12(4), 783-797.

Elliott, M., Browne, K., \&Kilcoyne, J. (1995). Child sexual abuse prevention: What offenders tell us. Child Abuse \& Neglect, 19(5), 579-594.

European Commission. (2013). Missing Children in the European Union: Mapping, data collection and statistics. Luxembourge: Publications Office for the European Union. Retrieved May $23^{\text {rd }} 2016$ from http://ec.europa.eu/justice/fundamentalrights/files/missing_children_study_2013_en.pdf

Exeter Press and Echo. (2015). Exeter stranger danger: Police advice on what to tell your children. Reported on $18^{\text {th }} \quad$ July, 2015.Retrieved $\quad$ May $23^{\text {rd }} 2016$ from http://www.exeterexpressandecho.co.uk/Exeter-Stranger-Danger-National-CrimePrevention/story-27440197-detail/story.html

Felson, M., \&Clarke, R.V. (1998).Opportunity makes the thief. Practical theory for crime prevention.Police Research Series, Paper 98.London: Home Office, Policing and Reducing Crime Unit.

Felson, M. 1995. Those who discourage crime.In Eck, J.E., \&Weisburd, D. (1995). (Eds.). Crime and place. Monsey, New York: Criminal Justice Press.

Finkelhor, D., Hammer, H., \&Sedlak, A.J. (2002).Nonfamily abducted children- National estimates and characteristics. Washington: US Department of Justice. 
Finkelhor, D., Hotaling, G., and Sedlak, A. (1992). The abduction of children by strangers and nonfamily members: Estimating the incidence using multiple methods. Journal of Interpersonal Violence 7(2):226-243.

Finkelhor, D., \&Ormrod, R. (2000).Kidnapping of juveniles: Patterns from NIBRS. Washington: US Department of Justice: Office of Juvenile Justice and Delinquency Prevention.

Fitzgerald, J., \& People, J. (2006). Victims of abduction: Patterns and case studies. BOCSAR NSW Crime and Justice Bulletins, 16.

Foster, S., Wood, L., Francis, J., Knuiman, M., Villanueva, K., \& Giles-Corti, B. (2015). Suspicious minds: Can features of the local neighbourhood ease parents' fears about stranger danger?.Journal of Environmental Psychology, 42, 48-56.

Greater Manchester Police.(2015). 60 second security-stranger danger. Crime Reduction. Retrieved on $23^{\text {rd }}$ May 2016 from http://www.gmp.police.uk/content/section.html?readform\&s=02BAEE119FECBC558025796 1003ADB7B

Groff, E. (2007). Simulation for Theory Testing and Experimentation: An Example Using Routine Activity Theory and Street Robbery. Journal of Quantitative Criminology, 23, 75-103. 
Gross, G. (2013). Safety tips to help avoid child abduction. Huffington Post. Reported on $16^{\text {th }}$ July 2013.Retrieved on $23^{\text {rd }}$ May 2016 from http://www.huffingtonpost.com/dr-gail-gross/safetytips-to-help-avoid-child-abduction_b_3282779.html

Hayden, C., \&Dlugosz, G. (2012). Secondary school children and the experience of robbery: A survey in three south London schools. Crime Prevention \& Community Safety, 14(2), 122139.

Heide, K.M., Beauregard, E., \& Myers, W.C. (2009). Sexually motivated child abduction murders: Synthesis of the literature and case illustration. Victims \& Offenders: An international Journal of Evidence-based Research, Policy, and Practice, 4(1), 58-75.

Her Majesty's Government. (2015). Working together to safeguard children: A guide to inter-agency working to safeguard and promote the welfare of children. Retrieved May $23^{\text {rd }} 2016$, from http://ec.europa.eu/justice/fundamental-rights/files/missing_children_study_2013_en.pdf

Hollis, M.E., Felson, M., \& Welsh, B.C. (2013). The capable guardian in routine activities theory: A theoretical and conceptual reappraisal. Crime Prevention and Community Safety, 15, pp6579.

Hollis-Peel, M. E., Reynald, D. M., van Bavel, M., Elffers, H., \& Welsh, B. C. (2011). Guardianship for crime prevention: A critical review of the literature. Crime, law and social change, 56(1), 53-70. 
Hollis-Peel, M. E., Reynald, D. M., \& Welsh, B. C. (2012). Guardianship and crime: an international comparative study of guardianship in action. Crime, law and social change, 58(1), 1-14.

Hollis-Peel, M.E., \& Welsh, B.C. (2014). What makes a guardian capable? A test of guardianship in action. Security Journal, 27, 320-337.

Jeffery, C.R. (1977). Crime Prevention Through Environmental Design. 2nd Edition. Beverly Hills: Sage.

Kennedy, L. W., \& Forde, D. R. (1990). Routine activites and crime: An analysis of victimization in Canada. Criminology, 28(1), 137-152.

Kids Health.(2015). Strategies for preventing abductions. Retrieved May $23^{\text {rd }} 2016$ http://kidshealth.org/parent/firstaid_safe/outdoor/abductions.html\#

Leclerc, B., Proulx, J., \& Beauregard, E. (2009).Examining the modus operandi of sexual offenders against children and its practical implications. Aggression and violent behavior, 14(1), 5-12.

Leclerc, B., \&Reynald, D. (2015).When scripts and guardianship unite: A script model to facilitate intervention of capable guardians in public settings. Security Journal.

Leclerc, B., Wortley, R., \& Smallbone, S. (2010). An exploratory study of victim resistance in child sexual abuse: Offender modus operandi and victim characteristics. Sexual abuse: a journal of research and treatment, 22(1), 25-41. 
Mackett, R. (2011). Letting children be free to walk. London: University College London, Centre for

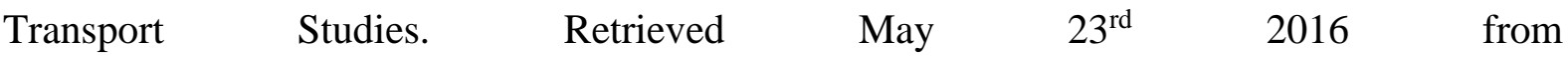
https://www.researchgate.net/profile/Roger_Mackett/publication/228521859_Letting_childre n_be_free_to_walk/links/0c96051d58c7dd3d56000000.pdf

Madriz, E.I. (997). Images of criminals and victims: a study on women's fear and social control. Gender and Society, 11(3), 342-356.

Mayhew, P. (1981). "Crime in Public View: Surveillance and Crime Prevention. "In: P.J. Brantingham and P.L. Brantingham (eds.), Environmental Criminology. Beverly Hills, CA: Sage. (Reprinted by Waveland Press, Prospect Heights, Illinois, 1991.)

Missing Kids UK. (2015). Parents and Carers Advice Pack. Retrieved on $15^{\text {th }}$ October 2015 from http://missingkids.co.uk/advice/advice-for-parents-guardians-and-teachers/

Mustaine, E.E., \& Tewksbury, R. (1999). A routine activity theory explanation for women's stalking victimizations. Violence Against Women, 5(1), 43-62.

National Centre for Missing and Exploited Children. (2015). Knowing my safety rules. Missing Kids. Retrieved May $23^{\text {rd }} 2016$ fromhttp://www.missingkids.com/en_US/publications/NC28.pdf

National Centre for Missing and Exploited Children. (2015). Going to and from school. Missing $\begin{array}{lllll}\text { Kids. } & \text { Retrieved } & \text { May } & 23^{\text {rd }} & 2016\end{array}$ http://www.missingkids.com/en_US/publications/NC28.pdf 
Newiss, G. (2016). Police-recorded child abduction and kidnapping 2014/15: England, Wales and Northern Ireland. London: Action Against Abduction.

Newiss, G., \& Collie, C. (2015).Police-recorded child abduction and kidnapping 2013/14: England, Wales and Northern Ireland. London: Parents and Abducted Children Together.

Newiss, G. (2014). Beyond stranger danger. London: Action Against Abduction (formerly Parents and Abducted Children Together).

Newiss, G., \& Fairbrother, L. (2004).Child abduction: understanding police recorded crime statistics. London: Home Office.

Newiss, G., \& Traynor, M. (2013). Taken. A study of child abduction in the UK. London: Action Against Abduction (formerly Parents and Abducted Children Together).

Newman, O. (1972). Defensible Space. New York, NY: Macmillan.

Noor-Mohamed, M. (2013). The definitional ambiguities of kidnapping and abduction, and its categorization: The case for a more inclusive typology. The Howard Journal of Criminal Justice, 53(1), 83-100.

Reynald, D. M. (2011). Factors associated with the guardianship of places: Assessing the relative importance of the spatio-physical and sociodemographic contexts in generating opportunities for capable guardianship. Journal of Research in Crime and Delinquency, 48(1), 110-142. 
Reynald, D.M., \& Elffers, H. (2009). The future of Newman's defensible space theory: Linking defensible space and the Routine Activities of Place. European Journal of Criminology, 6(1), $\mathrm{p} 25$.

Reynald, D.M., \& Elffers, H. (2016). The routine activity of guardianship: Comparing self-reports of guardianship intensity patterns with proxy measures. Crime Prevention \& Community Safety, $17,221-232$.

Shutt, J. E., Miller, J. M., Schreck, C. J., \& Brown, N. K. (2004).Reconsidering the leading myths of stranger child abduction. Criminal Justice Studies, 17(1), 127-134.

Smith, R. G., \& Jorna, P. (2011). Fraud in the 'outback': Capable guardianship in preventing financial crime in regional and remote communities. Trends and Issues in Crime and Criminal Justice, (413), 1.

Sweeney, S. M., \& Von Hagen, L. A. (2016). Stranger danger, cell phones, traffic, and active travel to and from schools: perceptions of parents and children. Transportation Research Record: Journal of the Transportation Research Board, (2582), 1-7.

Reynald, D. M. (2010). Guardians on guardianship: Factors affecting the willingness to supervise, the ability to detect potential offenders, and the willingness to intervene. Journal of Research in Crime and Delinquency, 47(3), 358-39. 
Reynald, D. M. (2011). Factors associated with the guardianship of places: Assessing the relative importance of the spatio-physical and sociodemographic contexts in generating opportunities for capable guardianship. Journal of Research in Crime and Delinquency, 48(1), 110-142.

Ross, A.S. (1971) Bystander intervention: The presence of children. Journal of personality and social psychology, 19(3), 306-310.

Tedisco, J. N., \& Paludi, M. A. (1996).Missing children: A psychological approach to understanding the causes and consequences of stranger and non-stranger abduction of children. SUNY Press.

Tillyer, M.S. \& Eck, J.E. (2010). Getting a handle on crime: A further extension of routine activities theory. Security Journal. Online First edition, doi: 10.1057.sj.2010.2.

Tewksbury, R. \& Mustaine, E.E. (2003). College students` lifestyles and self-protective behaviors: Further considerations of the guardianship concept in routine activity theory. Criminal Justice and Behavior, 30(3), 302-327.

Tilley, N. (2009) Crime Prevention. Cullompton, UK: Willan.

Welsh, B.C., \& Farrington, D.P. (2006). Surveillance for crime prevention in public space: Results and policy choices in Britain and America. Criminology and Public Policy, 3(3), pp497-526.

Yar, M. (2014). The novelty of 'cybercrime'. An assessment in light of routine activity theory. European Journal of Criminology, 2(4), 407-427. 